\title{
フラーレン薄膜を利用した透明導電膜の形成
}

\author{
新井龍 $-1, *_{1}$ 古川雄 $-1, * 1$ \\ 1 東海大学大学院工学研究科金属材料工学専攻 \\ 2 東海大学工学部材料科学科 \\ J. Japan Inst. Met. Mater. Vol. 77, No. 3 (2013), pp. 59-63 \\ (C) 2013 The Japan Institute of Metals and Materials
}

森島雅 人, $^{2,2}$

葛 巻 徹 2

\section{Formation of a Transparent Electroconductive Film Derived from Fullerene Thin Film}

\author{
Ryuichi Arai ${ }^{1, * 1}$, Yuichi Furukawa ${ }^{1, * 1}$, Masato Morishima ${ }^{2, * 2}$ and Toru Kuzumaki ${ }^{2}$ \\ ${ }^{1}$ Department of Metallurgical Engineering, Graduate School of Engineering, Tokai University, Hiratsuka 259-1292 \\ ${ }^{2}$ Department of Materials Science, School of Engineering, Tokai University, Hiratsuka 259-1292
}

\begin{abstract}
Recently, with increase of demand of flat panel displays, it is required to develop a transparent electroconductive film without using a rare metal. In this study, we carried out the formation of a transparent electroconductive film derived from fullerene. $\mathrm{C}_{60}$ was evaporated on a quartz substrate, and then we irradiate ultraviolet light on the films for 72 or $120 \mathrm{~h}$, respectively. After the irradiation, nickel thin film formed on the $\mathrm{C}_{60}$ film, and then heat-treatment was carried out in an electric furnace with a vacuum of $10^{-4} \mathrm{~Pa}$. Raman spectra showed that $\mathrm{C}_{60}$ films were polymerized by ultraviolet light irradiation. Although polymerized $\mathrm{C}_{60}$ films tended to become amorphous structure by heat-treatment of $873 \mathrm{~K}$ for $10 \mathrm{~min}$, the films covered with nickel as a catalyst tended to be graphitized by the same treatment. The obtained films indicated transparency, and the minimum electrical resistivity was $10^{-3} \Omega \mathrm{cm}$.
\end{abstract}

(Received October 16, 2012; Accepted November 26, 2012; Published March 1, 2013)

Keywords: fullerene, graphene, Raman spectrum, transparent electroconductive film, ultraviolet irradiate

\section{1. 緒言}

近年フラットパネルディスプレイ(FPD)を始めとする透 明電極の需要が増大している. 現在, 主に使用されている透 明電極は酸化インジウムスズ(ITO)である.ITOに含まれ るインジウムは希土類元素の一種であり, 使用量の増加に伴 って資源としての枯渴が懸念されている. そのため, ITO の代替材料の開発が期待されている.その一つとしてナ, カーボン材料に関する研究報告1-5) が盛んに行われており, 特に高電子移動度 $\left(\sim 200000 \mathrm{~cm}^{2} / \mathrm{Vs}\right)^{6)}$, 光透過性 $(90 \%$ 7) から, グラフェンの透明電極への応用が期待され ている.グラフェンを透明電極として応用するためには, ガ ラス基板上に低温かつ大面積で合成する必要がある. 現在検 討されている方法としては, 炭化水素系ガスを用いた CVD 法が主流である.しかし，この方法ではグラフェンの層数制 御が難しく, 均一な膜の大面積化には至っていない。 また, 通常用いられる FPD 用ガラス基板の耐熱温度以下での合成 が困難であるためガラス基板上への直接合成は実現されてい ない．そこで本研究ではフラーレンを出発材料として紫外線 や熱処理等での相変態を利用し, 均一なグラフェンを低温か つ大面積で合成することを試みる， $\mathrm{C}_{60}$ 分子はサッカーボー

*1 東海大学大学院生 (Graduate Student, Tokai University)

*2 東海大学学生 (Undergraduate Student, Tokai University)
ル型の閉殼構造を持ち, Langmuir-Blodgett 法を用いること で層数を分子レベルで制御できる ${ }^{8)}$. また， $\mathrm{C}_{60}$ 分子への紫 外線, 電子線照射により $\mathrm{C}_{60}$ 分子同士がポリマー化すること が報告されている ${ }^{9,10)}$. 本研究では, ガラス基板上に $\mathrm{C}_{60}$ 単 分子膜を層数制御して形成し, 紫外線照射抢よび熱処理を施 すことで炭素原子配列の再構成を促し $1 \sim 3$ 層レベルの均一 なグラフェンを形成することを目指している. 本報告では, その基礎的検討として, 抵抗加熱蒸着により作製した $\mathrm{C}_{60}$ 薄 膜に対し，(1)紫外線照射および熱処理を行った場合と(2)紫外 線照射後の $\mathrm{C}_{60}$ 薄膜に触媒としてニッケル $(\mathrm{Ni})$ 層を形成した 後, 熱処理を行った場合のそれぞれについて構造解析および 電気抵抗測定を行い, 構造と電気的特性との関係について検 討した。

\section{2. 実 験 方 法}

\section{1 試料作製}

Fig. 1 に本実験の試料作製プロセスの概略を示す． $\mathrm{C}_{60}$ 薄 膜は $\mathrm{C}_{60}$ 粉末(純度 $99.95 \%, \mathrm{MTR}$ Ltd.) から，スライドガラ スを基板として抵抗加熱真空蒸着装置 $(\mathrm{JEE}-400, \mathrm{JEOL}) に$ より成膜を行った. 到達真空度は $6.0 \times 10^{-4} \mathrm{~Pa}$, 蒸着源の 温度は $600 \sim 620^{\circ} \mathrm{C}$, 蒸着時間は $30 \mathrm{~min}$ とした。作製した $\mathrm{C}_{60}$ 薄膜に対して Fig. 2 に示す紫外線照射装置 (HE1000C, SEN Light Corp.) を用いて, 大気中にて紫外光を照射した.

Table 1 に紫外線照射条件を示す. 今回は出力および照射時 


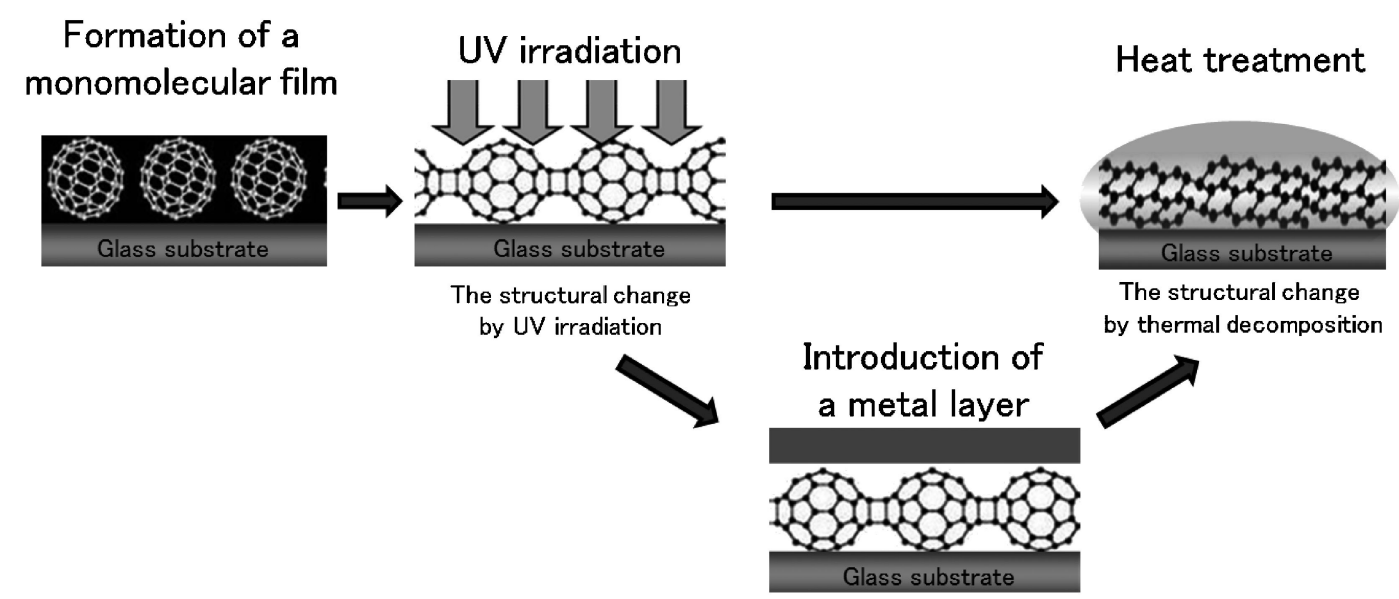

Fig. 1 Schematic diagram of sample preparations in this experiment.

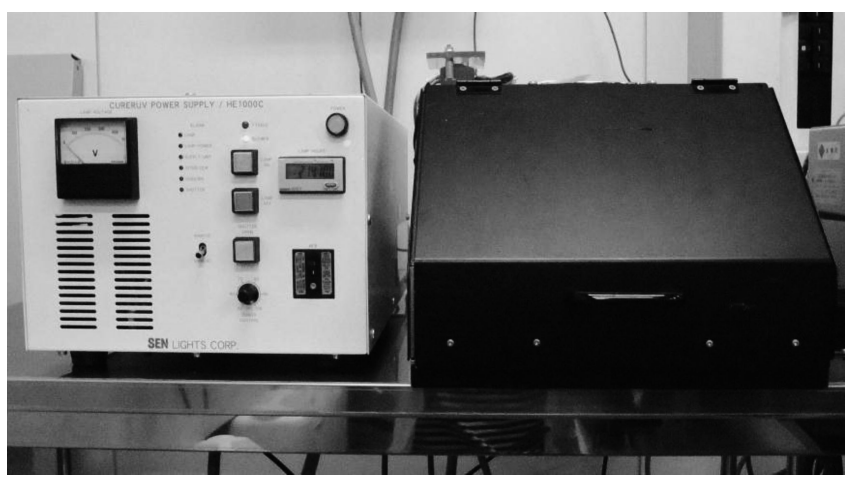

Fig. 2 Photograph of an ultraviolet light irradiation system.

Table 1 Conditions of ultraviolet irradiation.

\begin{tabular}{lccr}
\hline Ramp type & \multicolumn{3}{c}{ High-pressure Hg lamp } \\
lrradiate time $/ \mathrm{h}$ & 500 & 700 & 1000 \\
Radiation output $/ \mathrm{W}$ & 343 & 373 & 413 \\
Temperature during irradiation/K & & \\
\hline
\end{tabular}

間をパラメータとして実験を行った．熱処理は赤外線イメー ジ炉 $\mathrm{HCP}-7000, \mathrm{ULVAC})$ を用いて, Ar 雾囲気中 $873 \mathrm{~K}$, 10 min で行った。 また, 触媒金属層として Ni を紫外線照射 後の $\mathrm{C}_{60}$ 薄膜上に約 $20 \mathrm{~nm}$ スパッタ堆積 $(\mathrm{SC}-701 \mathrm{HMC} I \mathrm{I}$, SANYU ELECTRON)させた試料も作製し，前出と同様の 条件で熱処理を行った. 形成された薄膜の膜厚測定は原子間 力顕微鏡 $(\mathrm{AFM}, \mathrm{Veeco})$ 抢よび走査型電子顕微鏡 $(\mathrm{SEM}$, JSM-5600 LV JEOL)を用いて行った。

\section{2 電気抵抗率測定}

四探針抵抗測定装置 $(\mathrm{K}-705 \mathrm{RH}, \mathrm{KYOWARIKEN})$ および 高抵抗試料の測定のためデジタルエレクトロメータ (8252, ADCMT)を用いて電気抵抗率の測定を行った. 測定は各試 料 3 点をとり, 平均を值とした。

\section{3 構造解析}

ラマン散乱分光分析法 (NSR-1000, JASCO)を用いて構造 解析を行った。励起レーザーは $\mathrm{Nd}: \mathrm{YVO}_{4}$ (波長 $532 \mathrm{~nm}$ )を

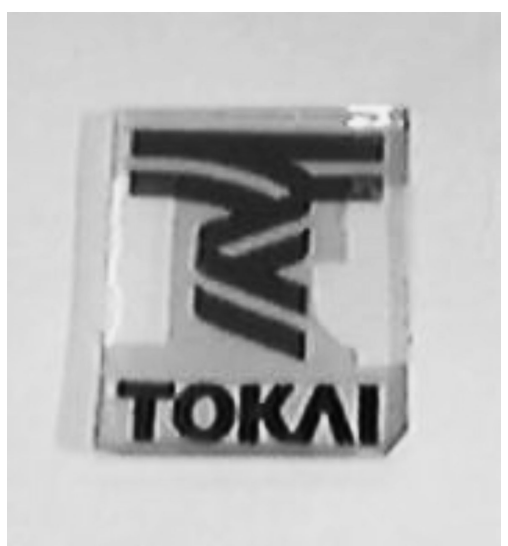

Fig. 3 Photographs of a pristine $\mathrm{C}_{60}$ thin film formed on a glass substrate. The film displays light yellow.

用い，露光時間は $15 \mathrm{~s}$ とした.

\section{3. 実験結果および考察}

Fig. 3 に作製した $\mathrm{C}_{60}$ 薄膜の試料を示す. 膜厚は約 200 nmであり，黄色味がかった色を呈している. Fig. 4 に作製 した未処理の $\mathrm{C}_{60}$ 薄膜および紫外線照射した $\mathrm{C}_{60}$ 薄膜の電気 抵抗率を示す. $\mathrm{C}_{60}$ 薄膜の電気抵抗率は $10^{11} \Omega \mathrm{cm}$ で絶縁体 の域に入る. 一方, 紫外線照射した試料は電気抵抗率の低下 が確認され約 $6 \times 10^{8} \Omega \mathrm{cm}$ であった. 紫外線照射による抵抗 率の低下は， $\mathrm{C}_{60}$ 分子のポリマー化によるものと考えられ る ${ }^{9-11)}$. 出力, 照射時間の増加とともに電気抵抗率が低下す るものと予測したが，今回の実験では出力，照射時間による 電気抵抗率の明確な違いは確認できなかった. Fig. 5 に紫外 線照射抢よび熱処理した $\mathrm{C}_{60}$ 薄膜の電気抵抗率を示す. 出 力, 照射時間の増加とともに電気抵抗率が低下する傾向を確 認できた. 紫外線照射 $1000 \mathrm{~W}, 120 \mathrm{~h}$ では抵抗率約 $1 \times 10^{7}$ $\Omega \mathrm{cm}$ を示した. 紫外線照射のみの場合, 照射出力による電 気抵抗率の違いは明確には確認できなかったが, 熱処理後に は照射出力および照射時間の影響が認められた．これは照射 面積がどの試料も一定と考えた場合, 照射時間が長いほどポ リマー化した組織が試料の深さ方向に広がり，その後の熱処 


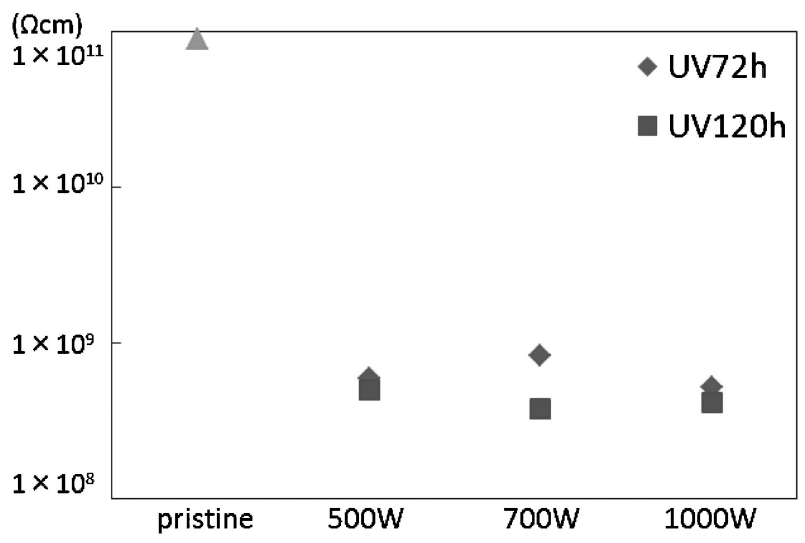

Fig. 4 Electrical resistivity of $\mathrm{C}_{60}$ thin films before and after ultraviolet irradiation.

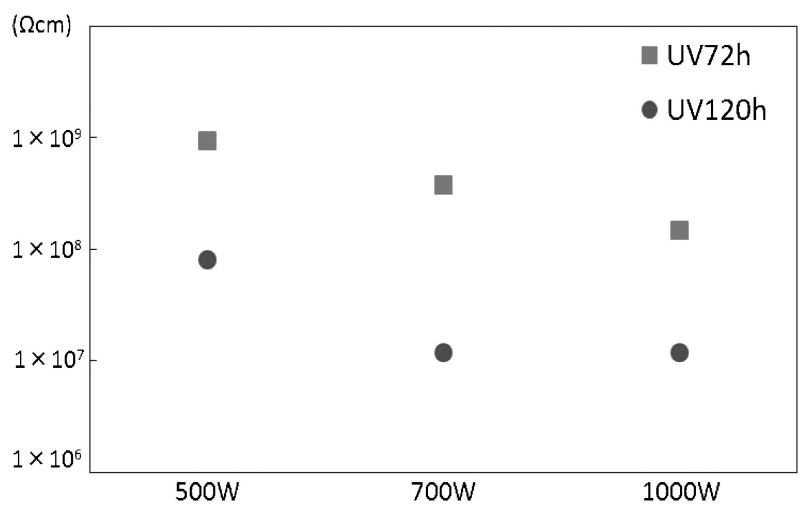

Fig. 5 Electrical resistivity of $\mathrm{C}_{60}$ thin films after ultraviolet irradiation and heat treatment of $873 \mathrm{~K}$ for $10 \mathrm{~min}$.

理による炭素原子配列の再構成が進行するためではないかと 推測される。ただし，本実験では照射時間が $120 \mathrm{~h}$ の場合， 出力 $700 \mathrm{~W}$ と $1000 \mathrm{~W}$ ではほぼ同じ抵抗率を示していた. この結果は照射条件に最適值があることを示しているのか, または，データのばらつきのためなのかは本データのみでは 判定できない. Fig. 6 に紫外線照射 $120 \mathrm{~h}$ および熱処理した 試料のラマンスペクトルを示す. 未処理の $\mathrm{C}_{60}$ 薄膜のラマン スペクトルでは $1480 \mathrm{~cm}^{-1}$ および $1570 \mathrm{~cm}^{-1}$ 付近に $\mathrm{C}_{60}$ 特 有のピークが確認できる. 紫外線照射および熱処理した試料 については $\mathrm{C}_{60}$ 特有のピークが残留しているものの 1480 $\mathrm{cm}^{-1}$ のピーク強度は減少し，ピークの低カイザー側や 1570 $\mathrm{cm}^{-1}$ 付近のピークもブロード化していることがわかる.こ の傾向は紫外線照射出力が上がるほど顕著となっている．ラ マンスペクトルは, 紫外線照射と熱処理によって $\mathrm{C}_{60}$ はアモ ルファス化する傾向にあるが， $\mathrm{C}_{60}$ に特徵的なピークが残留 していることから球殼構造が一部残った構造になっているこ とを示している. また, 抵抗率が $10^{7} \Omega \mathrm{cm}$ オーダーである ことからも紫外線照射と熱処理のみの方法ではグラフェンの 形成が難しいと判断される，そこで本実験では紫外線照射を 施した $\mathrm{C}_{60}$ 薄膜上に触媒金属として $\mathrm{Ni}$ 層を導入し, 熱処理 によるグラフェンの形成を試みた. Fig. 7 に紫外線照射 120 $\mathrm{h}$ 後に $\mathrm{Ni}$ 層を導入し熱処理した試料の電気抵抗率を示した. $500 \mathrm{~W}$ では高い值を示しているものの $700,1000 \mathrm{~W}$ で照射

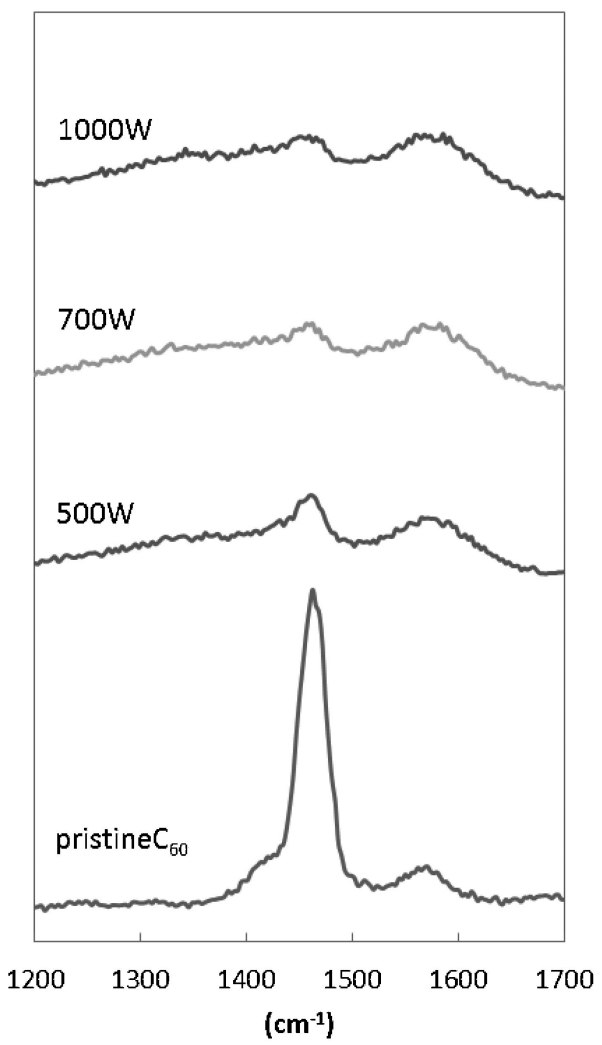

Fig. 6 Raman spectra of a pristine $\mathrm{C}_{60}$ thin film and the treated film on each output of ultraviolet irradiation for $120 \mathrm{~h}$ and heat treatment of $873 \mathrm{~K}$ for $10 \mathrm{~min}$.

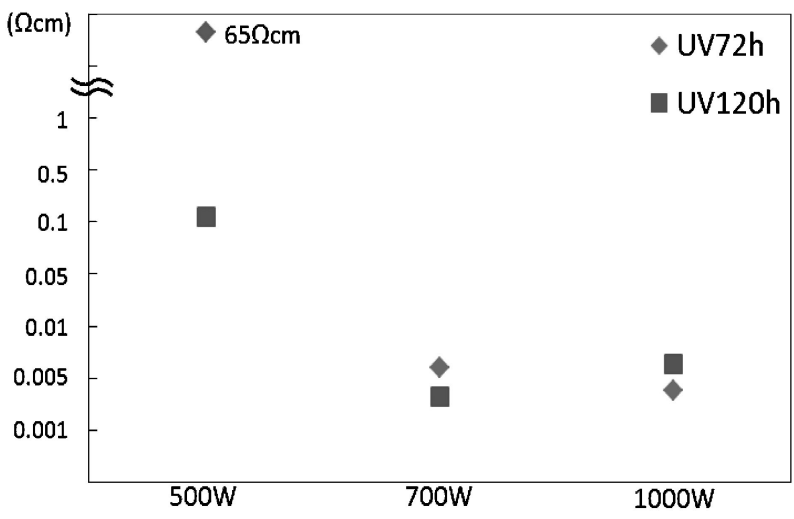

Fig. 7 Electrical resistivity of $\mathrm{C}_{60}$ thin films with Ni catalyst after ultraviolet irradiation and heat treatment of $873 \mathrm{~K}$ for 10 min.

した試料の電気抵抗率は大幅な減少が確認され $700 \mathrm{~W}, 120$ $\mathrm{h}$ では約 $4 \times 10^{-3} \Omega \mathrm{cm}$ を示した. 本実験では抵抗率に及ぼ す出力や照射時間の違いはあまり明確ではなく, Fig. 7 は前 出の Fig. 5 で検討したように, 照射条件には最適值がある ことを示唆する結果であると考える. Fig. 8 に Ni 層を導入 した場合のラマンスペクトルを示す．紫外線照射時間は 120 $\mathrm{h}$ で熱処理を施した試料である. $500 \mathrm{~W}$ では $\mathrm{C}_{60}$ 特有のピー

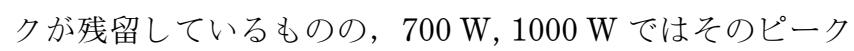
が完全に消失している．さらに， $1360 \mathrm{~cm}^{-1}(\mathrm{D}$ バンド), $1590 \mathrm{~cm}^{-1}$ ( G バンド)付近に新たなピークが形成されていた. $\mathrm{D}$ バンドはアモルファスカーボン等のダングリングボンド 
を持つ炭素原子や原子欠陥に起因するものであり， $\mathrm{G}$ バンド は $\mathrm{sp}^{2}$ 混成軌道の炭素原子の六角格子内振動に起因するもの である. また，出力 $700 \mathrm{~W}$ では Fig. 9 に示すように, 2700 $\mathrm{cm}^{-1}$ 付近に $2 \mathrm{D}$ バンドが見られた. $\mathrm{G}$ バンドと $2 \mathrm{D}$ バンド との比からグラフェンの層数を見積もると, 本試料では 5 層以上のグラフェンが形成されていると考えられる12)。こ れらの構造解析の結果から, 紫外線照射と $\mathrm{Ni}$ 層の導入およ び熱処理における電気抵抗率の低下は, 炭素の六員環ネット ワーク構造の再構成による多層グラフェンの形成によるもの

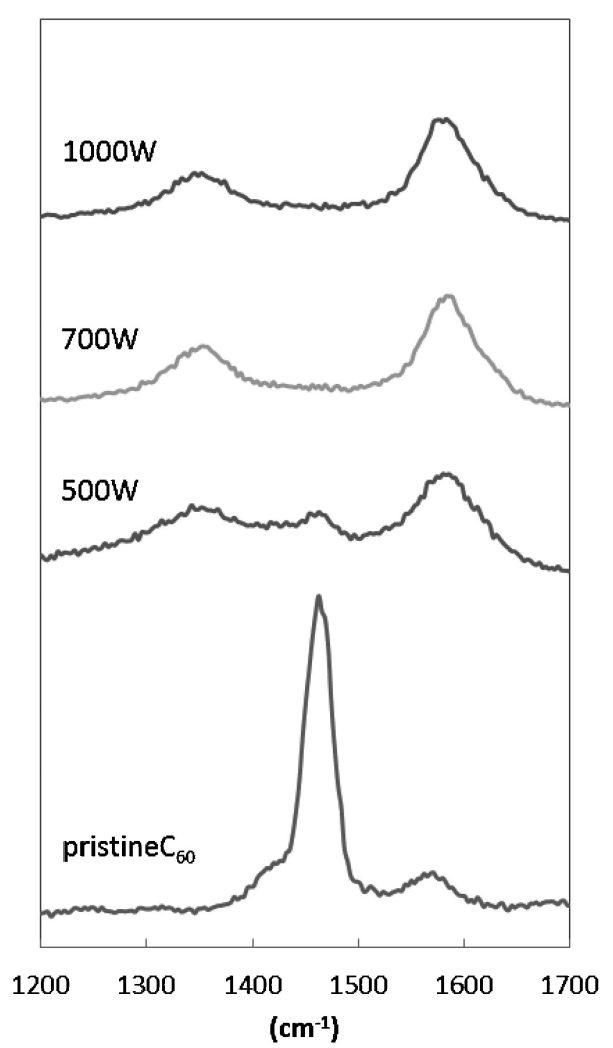

Fig. 8 Raman spectra of a pristine $\mathrm{C}_{60}$ thin film and the treated film with $\mathrm{Ni}$ catalyst on each output of ultraviolet irradiation for $120 \mathrm{~h}$ and heat treatment of $873 \mathrm{~K}$ for $10 \mathrm{~min}$.
と推察される。しかしその一方で, 電気抵抗率の低下の原因 は構造変化のみならず膜表面への不純物の吸着による影響も 考える必要がある．電気伝導度の変化の要因を明らかにする ためには, 今後透過型電子顕微鏡観察による構造解析, さら には, ホール効果の測定により詳細な検討を行う必要がある.

Fig. 10 に Ni 層を導入して作製した試料を示す。本試料は 紫外線照射 $1000 \mathrm{~W}, 120 \mathrm{~h}$ で熱処理 $(873 \mathrm{~K}, 10 \mathrm{~min})$ を施し たものである. Fig. 3 と比較すると, 触媒として導入した $\mathrm{Ni}$ が残留しているためかやや灰色がかっており若干のムラ が見られるが，透明性は確保できていることがわかる。測定 された試料の電気抵抗率(約 $4 \times 10^{-3} \Omega \mathrm{cm}$ ) は $\mathrm{Ni} の そ れ($ 約 $\left.7 \times 10^{-6} \Omega \mathrm{cm}\right)$ と比較して十分大きく，電気抵抗率の変化は グラフェン形成によるものと考えられる. しかし, 抵抗率測 定に及ぼす $\mathrm{Ni}$ 触媒の影響の見積もりが難しいため，今後酸 処理等により $\mathrm{Ni}$ の影響を排除しての測定が必要である. 以 上の結果から， $\mathrm{C}_{60}$ 薄膜は紫外線照射および熱処理により球 殼状構造の特徵を失いアモルファス化する傾向にあるが, グ ラフェンの形成には金属触媒層の導入が有効で, 紫外線照射 がより低温でのグラフェン形成に寄与していると考えられる.

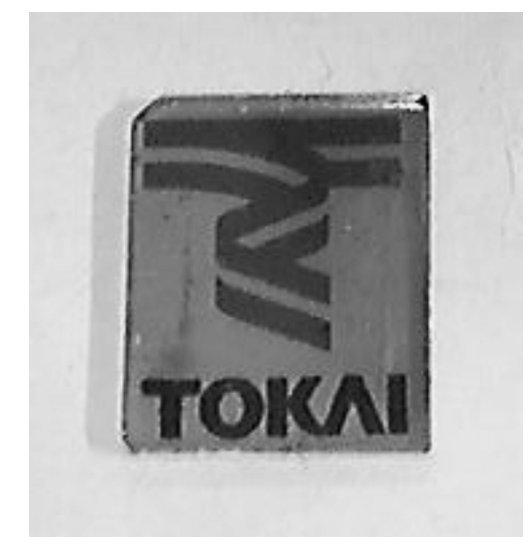

Fig. 10 A transparent film formed on glass. The film derived from $\mathrm{C}_{60}$ film with $\mathrm{Ni}$ catalyst. The specimen produced by ultraviolet irradiation of $700 \mathrm{~W}$ for $120 \mathrm{~h}$ and heat treatment of $873 \mathrm{~K}$ for $10 \mathrm{~min}$.

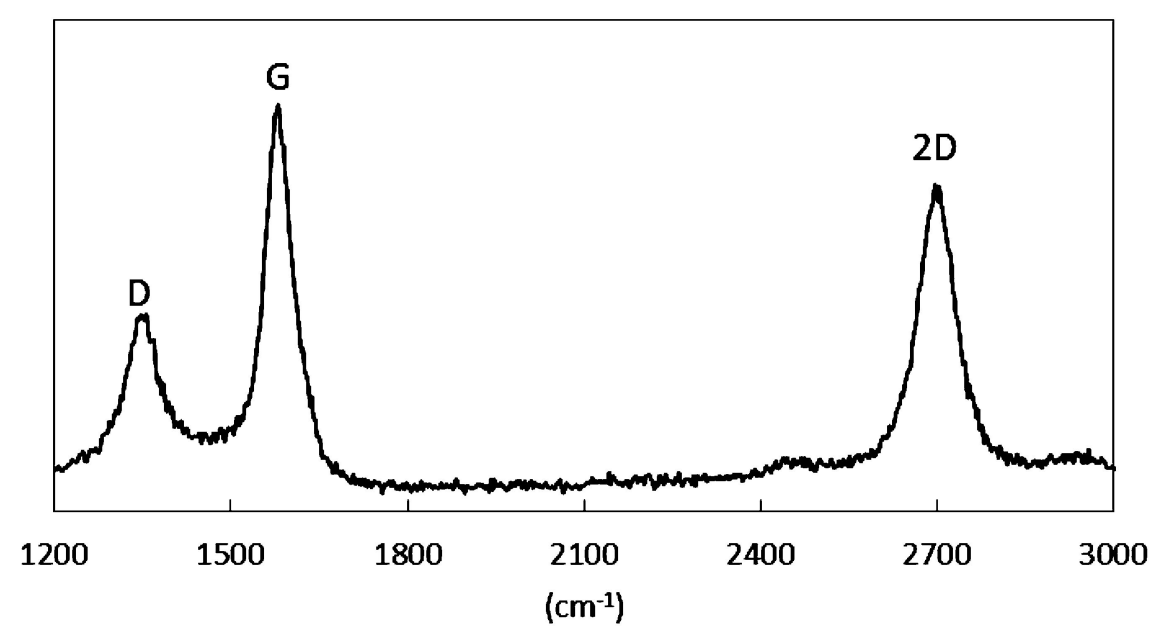

Fig. 9 Raman spectrum of $\mathrm{C}_{60}$ thin film with $\mathrm{Ni}$ catalyst after ultraviolet irradiation of $700 \mathrm{~W}$ for $120 \mathrm{~h}$ and heat treatment of $873 \mathrm{~K}$ for $10 \mathrm{~min}$. 
$\mathrm{Ni}$ 層を導入するプロセスでは, 照射出力 $700 \mathrm{~W}$ 以上および 照射時間 $72 \mathrm{~h}$ 以上は最終的に得られる抵抗率に顕著な違い を与えていなかったため，照射条件には最適值があると考え られる. 今後, 紫外線照射時の䨌囲気や照射時の試料の温度 管理も含めてさらに実験条件について詳細に検討し, グラフ ェン形成のためのプロセス条件の最適化が必要である.

\section{4. 結 言}

本実験では， $\mathrm{C}_{60}$ 薄膜に対する紫外線照射と熱処理，さら には金属触媒層を導入したプロセスによるグラフェンの形成 を試みた．結果として金属触媒層を導入したプロセスでは， 電気抵抗率の大幅な低下が確認された。 また，ラマンスペク トルから炭素原子の再配列により六員環ネットワーク構造の 形成が示され，多層ではあるが目的とするグラフェンが得ら れていることを示唆する結果を得た．本実験から紫外線照射 が低温 $(873 \mathrm{~K})$ での構造変化に寄与していると考えられる. より透明度が高く均質なグラフェン膜の合成のためには，出 発材料である $\mathrm{C}_{60}$ 薄膜の膜厚と金属触媒層の膜厚や紫外線照 射条件の制御等，グラフェン形成条件の最適化および電気伝 導度変化の要因について詳細に検討する必要がある。
ラマン分光測定には，東京工業大学の大竹尚登教授にご協 力頂きました。 心より御礼申し上げます。

文献

1) L. Gengchiau, N. Neophytos, M. S. Lundstrom and D. E Nikonov: IEEE Trans. Electron Devices 54(2007) 677-682.

2) V. Ryzhii and M. Ryzhii: Appl. Phys. Express 1(2008) 013001.

3) B. Obradovic and R. Kotlyar: Appl. Phys. Lett. 88(2006) 142102

4) J. Kim, M. Ishihara, Y. Koga, K. Tsugawa, M. Hasegawa and S. Iijima: Appl. Phys. Lett. 98(2011) 091502.

5) A. K. Geim: Science 324(2009) 1530

6) K. I. Bolotin, K. J. Sikes, Z. Jiang, M. Klima, G. Fudenberg, J. Hone, P. Kim and H. L. Stormer: Solid State Commun. 146 (2008) 351-355.

7) R. R. Nair, P. Blake, A. N. Grigorenko, K. S. Novoselov, T. J. Booth, T. Stauber, N. M. R. Peres and A. K. Geim: Science $\mathbf{3 2 0}$ (2008) 1308

8) G. Williams, A. J. Moore, M. R. Bryce, M. C. Petty and Y. M. Lvov: Synth. Met. 56(1993) 2955-2960.

9) A. M. Rao, P. Zhou, K.-A. Wang, G. T. Hager, J. M. Holden, Y. Wang, W.-T. Lee, X.-X. Bi, P. C. Eklund, D. S. Cornett, M. A Duncan and I. J. Amster: Science 259(1993) 955.

10) J. Onoe, T. Nakayama, M. Aono and T. Hara: Appl. Phys. Lett. $82(2003) 595$

11) A. M. Rao, P. C. Eklund, J. L. Hodeau, L. Marques and M. N. Regueiro: Phys. Rev. 55(1997) 4766-4773.

12) H. Zhou, C. Qiu, Z. Liu, H. Yang, L. Hu, J. Liu, H. Yang, C. Gu and L. Sun: J. Am. Chem. Soc. 132 (2010) 944-946. 